\title{
PENATALAKSANAAN BATU GINJAL DENGAN STONE BURDEN LEBIH DARI DUA SENTIMETER DI RUMAH SAKIT PUSAT ANGKATAN DARAT GATOT SUBROTO TAHUN 2011-2014
}

\author{
Octoveryal Aslim ${ }^{1}$, Nugroho Budi Utomo², Nindra Prasidja², Robertus Bebet Prasetyo ${ }^{2}$ \\ ${ }^{1}$ Departemen Urologi, Fakultas Kedokteran, Universitas Indonesia/ Rumah Sakit Pusat Cipto Mangunkusumo, \\ Jakarta. Korespondensi: octoaslim@gmail.com \\ ${ }^{2}$ Divisi Urologi, Departemen Bedah, Rumah Sakit Pusat Angkatan Darat Gatot Subroto, Jakarta.
}

\begin{abstract}
ABSTRAK
Tujuan: untuk mengetahui perbandingan lama operasi, lama perawatan paska operasi, jumlah perdarahan, komplikasi, angka bebas batu, dan hubungan antara komponen tersebut pada operasi percutaneous nephrolithotomy (PCNL) dan operasi terbuka baik, pyelolithotomy maupun extended pyelolithotomy sebagai penatalaksanaan batu ginjal dengan stone burden lebih dari $2 \mathrm{~cm}$. Metode: pengumpulan data dilakukan secara retrospektif yang diambil dari rekam medis pasien batu ginjal yang menjalani PCNL dan operasi terbuka di Rumah Sakit Pusat Angkatan Darat (RSPAD) Gatot Soebroto sepanjang tahun 2011 hingga tahun 2014. Hasil: dari 116 pasien dengan usia antara 22-73 tahun, mayoritas laki-laki, didapatkan hasil perbedaan yang bermakna secara statistik pada lama operasi $(\mathrm{p}=0,001)$, lama rawat paska operasi $(\mathrm{p}=0,011)$, dan komplikasi demam paska operasi $(\mathrm{p}=0,048)$, antara PCNL dan operasi terbuka. Sedangkan untuk parameter angka bebas batu dan jumlah perdarahan, tidak didapatkan perbedaan yang bermakna secara statistik $(\mathrm{p}=0,245$ dan $\mathrm{p}=0,154)$. Pada kelompok PCNL dan operasi terbuka, terdapat hubungan yang bermakna pada lama operasi dengan stone burden $(\mathrm{p}=0,004$ dan $\mathrm{p}=0,02)$ maupun letak batu $(\mathrm{p}<0,001$ dan $\mathrm{p}=0,011)$. PCNL memerlukan lama operasi dan lama rawat paska operasi yang lebih singkat, serta komplikasi demam paska operasi yang lebih sedikit, dibandingkan operasi terbuka. Namun demikian, untuk angka bebas batu dan jumlah perdarahan, tidak berbeda bermakna pada kedua kelompok. Terdapat hubungan yang bermakna secara statistik pada lama operasi dengan stone burden dan letak batu pada kedua kelompok. Simpulan: PCNL merupakan prosedur minimal invasif yang efektif dan aman dalam tatalaksana batu ginjal lebih besar dari $2 \mathrm{~cm}$ atau batu ginjal kompleks.
\end{abstract}

Kata kunci: percutaneous nephrolithotomy, pyelolithotomy, extended pyelolithotomy, batu pielum, angka bebas batu.

\section{TREATMENT OF KIDNEY STONE WITH STONE BURDEN MORE THAN TWO CENTIMETERS IN GATOT SOEBROTO INDONESIA ARMY CENTRAL HOSPITAL IN 2011-2014}

\footnotetext{
Octoveryal Aslim $^{1}$, Nugroho Budi Utomo ${ }^{2}$, Nindra Prasidja ${ }^{2}$, Robertus Bebet Prasetyo ${ }^{2}$

${ }^{1}$ Department of Urology, Faculty of Medicine Indonesia University/Cipto Mangunkusumo Central Hospital, Jakarta.

${ }^{2}$ Urology Division, Department of Surgery, Gatot Soebroto Indonesia Army Central Hospital, Jakarta.
}

\begin{abstract}
Objective: to determine the association between length of operation, post operative length of stay, amount of bleeding, complication, stone free rate, and the association between these factors as in patients who undergo percutaneous nephrolithotomy (PCNL) or open surgery for kidney stone with stone burden more than $2 \mathrm{~cm}$. Methods: the data was collected retrospectively from medical record of
\end{abstract}


patients with kidney stones with stone burden $>2 \mathrm{~cm}$ who undergo PCNL or open surgery in Gatot Soebroto Indonesia Army Central Hospital from 2011 until 2014. Results: one hundred sixteen patients were included in this study with the range of age was 22-73 years old and the majority of patients were man. Our study found statistically significant association between length of operation $(\mathrm{p}=0.001)$, postoperative length of stay $(\mathrm{p}=0.011)$, and postoperative complication $(\mathrm{p}=0.048)$ between PCNL and open surgery. However, no statistically significant association on stone free rate $(\mathrm{p}=0.245)$, amount of bleeding $(\mathrm{p}=0.154)$ between the two groups. We also found that there was a statistically significant association between lengths of operation with stone burden $(\mathrm{p}=0.004$ and $\mathrm{p}=0.02)$ and stone location $(\mathrm{p}<0.001$ and $\mathrm{p}=0.011)$ in both of them. PCNL had shorter length of operation and postoperative length of stay, fewer postoperative complication compared with open surgery. However, no difference between PCNL and open surgery in stone free rate and amount of bleeding outcome. There was statistically significant association between length of operation and stone burden in two groups of patients. Conclusion: PCNL is effective and safely minimal invasive procedure to treat kidney stone more than $2 \mathrm{~cm}$ or complex kidney stones.

Keywords: percutaneous nephrolithotomy, pyelolithotomy, extended pyelolithotomy, pyelum stone, stone free rate.

\section{PENDAHULUAN}

Peningkatan prevalensi global batu saluran kemih berhubungan dengan membaiknya sistem pemeliharaan kesehatan negara industri dan menurunnya kesenjangan sosial dalam masyarakat dunia. ${ }^{1}$ Prevalensi batu saluran kemih di Amerika Serikat menjadi dua kali lipat dibanding pada tahun $1960 .^{2-5}$

Penyakit batu saluran kemih masih merupakan penyakit dengan porsi terbesar dari jumlah pasien urologi di Indonesia. Selama kurun waktu 1997 hingga 2002 terdapat 2439 penderita batu ginjal di Rumah Sakit Umum Pusat Cipto mangunkusumo (RSCM) dengan jumlah tindakan yang dilakukan sebanyak 3.165 tindakan. Prevalensi penyakit antara lakilaki dan perempuan diperkirakan 3 berbanding 1 , dengan puncak usia dekade keempat dan kelima. ${ }^{6}$

Perkembangan teknologi di bidang kedokteran telah mengubah pendekatan intervensi bedah pada kasus batu ginjal (khususnya batu ginjal dengan stone burden $>2 \mathrm{~cm}$ ), dari operasi terbuka menjadi operasi endoskopi. Sebelumnya, GilVernet pada tahun 1965 mempelopori teknik operasi terbuka extended pyelolithotomy, yang kemudian menjadi prosedur pilihan dalam tatalaksana batu ginjal. Akses perkutan kedalam sistem pelviokalises pertama kali diperkenalkan pada tahun 1955 oleh Willard Goodwin, lalu menjadi rutin dilakukan sejak awal dekade 1980-an dan hingga kini menjadi pilihan utama tatalaksana batu ginjal. ${ }^{7-10}$

Tujuan utama dari tatalaksana bedah batu ginjal adalah mencapai angka bebas batu maksimal dengan morbiditas yang minimal dan tetap mempertahankan fungsi ginjal. ${ }^{11}$ Prosedur atau pilihan tindakan untuk batu ginjal antara lain extracorporeal shockwave lithotripsy (ESWL), ureterorenoscopy (URS) flexible, percutaneous nephrolithotomy (PCNL), dan tindakan operasi terbuka. ${ }^{11,12}$

Penelitian ini dilakukan untuk mengetahui perbandingan lama operasi, lama perawatan paska operasi, jumlah perdarahan, komplikasi dan angka bebas batu antara PCNL dan operasi terbuka pada 
batu ginjal yang memiliki stone burden $>2$ $\mathrm{cm}$. Diharapkan penelitian ini dapat menjadi salah satu sumber referensi bagi pemilihan tindakan untuk operasi batu ginjal dengan stone burden $>2 \mathrm{~cm}$.

\section{METODE}

Data diambil secara retrospektif dari rekam medis pasien penderita batu ginjal di RSPAD Gatot Soebroto, Jakarta sejak tahun 2011 hingga tahun 2014. Didapatkan data 116 pasien, sebanyak 69 pasien menjalani operasi PCNL dan 47 pasien menjalani operasi terbuka.

Data yang dikumpulkan meliputi jenis kelamin, usia, stone burden, letak batu, lama operasi, lama rawat paska operasi, jumlah perdarahan, komplikasi demam paska operasi, transfusi paska operasi, dan angka bebas batu.

Kriteria inklusi meliputi seluruh pasien batu ginjal dengan stone burden lebih dari $2 \mathrm{~cm}$, meliputi batu pielum, batu multipel pielum dan kaliks, dan batu cetak ginjal. Kriteria eksklusi adalah seluruh kasus yang tidak termasuk kriteria inklusi dan pasien dengan data yang tidak lengkap.

Data kemudian dianalisis dengan menggunakan SPSS untuk Mac versi 20.0. Analisis bivariat menggunakan uji hipotesis Kolmogorov-Smirnov untuk data numerik, dan uji Chi-Square, Fisher exact, KruskalWallis serta post hoc Mann-Whitney U untuk data kategorik.

Definisi stone burden atau ukuran batu adalah jumlah ukuran linier diameter terpanjang. ${ }^{11,13}$ Batu cetak ginjal adalah batu ginjal yang mengisi pielum hingga satu atau lebih kaliks ginjal. Dimana ukuran batu cetak diukur berdasarkan ukuran diameter linier terpanjang. ${ }^{11,13}$ Angka bebas batu adalah kondisi dimana tidak ditemukan adanya batu sisa paska operasi. ${ }^{11}$ Batu sisa paska operasi dinilai dengan menggunakan foto polos abdomen dan atau USG. Pecutaneous nephrolithotomy (PCNL) merupakan salah satu tindakan minimal invasif di bidang urologi yang bertujuan mengangkat batu ginjal dengan menggunakan akses perkutan untuk mencapai sistem pelviokalises. ${ }^{11}$

\section{HASIL}

Terdapat 116 pasien yang menjalani operasi batu ginjal dengan stone burden lebih dari $2 \mathrm{~cm}$, dimana 47 pasien menjalani operasi terbuka dan 69 pasien menjalani PCNL. Profil pasien tersebut di atas, dengan berbagai parameter dan analisisnya secara statistik, dapat dilihat pada tabel 1.

Pada penelitian ini terdapat 116 pasien dengan rentang usia antara 22 hingga 73 tahun dan jenis kelamin pria lebih banyak dibanding wanita, yakni 68 pria dan 48 wanita.

Stone burden lebih besar pada pasien PCNL. Lama operasi dan lama rawat paska operasi juga lebih singkat pada pasien yang menjalani PCNL, keduanya bermakna secara statistik. Sebenarnya jumlah perdarahan dan angka bebas batu juga lebih baik pada PCNL, namun demikian perbedaan keduanya tidak bermakna secara statistik. Angka kejadian demam paska operasi lebih banyak pada pasien operasi terbuka.

Pada tabel 2, 3, 4, dan 5 ditampilkan pengkajian hubungan antara stone burden dengan perdarahan dan batu sisa. Dari hasil di atas diperoleh bahwa tidak terdapat hubungan bermakna antara parameterparameter tersebut baik pada kelompok PCNL maupun pada kelompok operasi terbuka $(p>0,05)$. 
Tabel 1. Profil Pasien dan Perbandingan tindakan PCNL dengan Operasi Terbuka

\begin{tabular}{|c|c|c|c|}
\hline & PCNL & $\begin{array}{l}\text { Operasi } \\
\text { terbuka }\end{array}$ & $\mathbf{p}$ \\
\hline Total Kasus & 69 & 47 & \\
\hline \multicolumn{4}{|l|}{ Jenis kelamin } \\
\hline Pria & $\begin{array}{c}38 \\
(55 \%)\end{array}$ & $\begin{array}{c}30 \\
(63,8 \%)\end{array}$ & \\
\hline Wanita & $\begin{array}{c}31 \\
(44,9 \%)\end{array}$ & $\begin{array}{c}17 \\
(36,2 \%)\end{array}$ & \\
\hline $\begin{array}{l}\text { Median usia } \\
\text { (rentang) }\end{array}$ & $\begin{array}{c}52 \\
(22-73)\end{array}$ & $\begin{array}{c}50 \\
(22-73)\end{array}$ & 0,362 \\
\hline $\begin{array}{l}\text { Lama operasi } \\
\text { (menit) }\end{array}$ & $\begin{array}{c}150 \\
(100-210)\end{array}$ & $\begin{array}{c}190 \\
(120-300)\end{array}$ & $<0,001$ \\
\hline \multicolumn{4}{|l|}{ Lama rawat } \\
\hline $\begin{array}{l}\text { paska operasi } \\
\text { (hari) }\end{array}$ & $\begin{array}{c}5 \\
(3-13)\end{array}$ & $\begin{array}{c}6 \\
(4-24)\end{array}$ & $0,011^{\mathrm{a}}$ \\
\hline \multicolumn{4}{|l|}{$\begin{array}{l}\text { Perdarahan } \\
(\mathrm{mL})\end{array}$} \\
\hline$<100$ & $29(42 \%)$ & $23(48,9 \%)$ & \\
\hline $100-200$ & $29(42 \%)$ & $12(25,5 \%)$ & 0,15 \\
\hline$>200$ & $11(15,9 \%)$ & $12(25,5 \%)$ & \\
\hline \multicolumn{4}{|l|}{ Stone burden } \\
\hline$<3 \mathrm{~cm}$ & $3(4,3 \%)$ & 0 & \\
\hline $3-5 \mathrm{~cm}$ & $19(27,5 \%)$ & $5(10,6 \%)$ & 0,007 \\
\hline$>5 \mathrm{~cm}$ & $47(68,1 \%)$ & $42(89,4 \%)$ & \\
\hline \multicolumn{4}{|l|}{ Letak batu } \\
\hline Batu Staghorn & $34(49$, & $31(66,0 \%)$ & \\
\hline Batu Multipel & $15(21,7 \%)$ & $7(14,9 \%)$ & $0,206^{\mathrm{d}}$ \\
\hline Batu Pielum & $20(29,0 \%)$ & $9(19,1 \%)$ & \\
\hline \multicolumn{4}{|l|}{ Batu sisa } \\
\hline $\mathrm{Ya}$ & $18(26,1 \%)$ & ) $17(36,2 \%)$ & 0,33 \\
\hline Tidak & $51(73,9 \%)$ & ) $30(63,8 \%)$ & \\
\hline Transfusi darah & $9(13 \%)$ & $8(17 \%)$ & $0,743^{b}$ \\
\hline $\begin{array}{l}\text { Demam paska } \\
\text { operasi }\end{array}$ & $3(4,3 \%)$ & $8(17 \%)$ & $0,048^{\mathrm{d}}$ \\
\hline
\end{tabular}

${ }^{\mathrm{a}}$ Kolmogorov-Smirnov, ${ }^{\mathrm{b}}$ Chi-Square, ${ }^{\mathrm{c}}$ MannWhitney U, ${ }^{\mathrm{d}}$ Fischer-exact

Pada tabel 6 dan 7 ditampilkan pengkajian hubungan antara stone burden dengan lama operasi. Dari hasil diatas diperoleh hubungan bermakna antara stone burden dengan lama operasi pada kelompok PCNL dan kelompok operasi terbuka $(\mathrm{p}<0,05)$ terutama pada stone burden $3-5 \mathrm{~cm}$ dan $>5 \mathrm{~cm}$.
Tabel 2. Analisis hubungan antara Stone Burden terhadap Jumlah Perdarahan pada PCNL

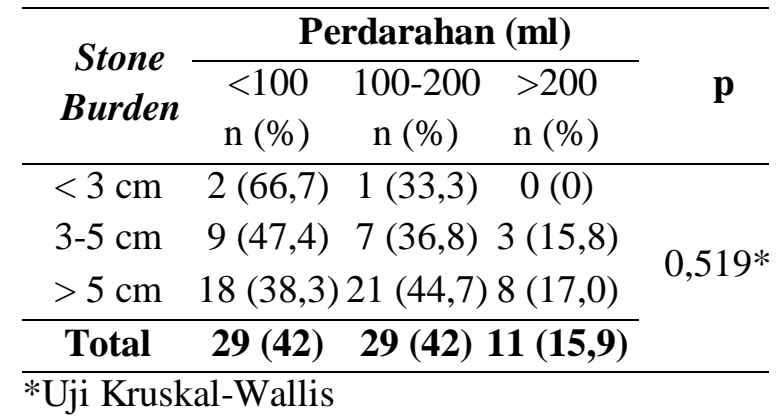

Tabel 3. Analisis hubungan antara Stone Burden terhadap Jumlah Perdarahan pada

Operasi Terbuka

\begin{tabular}{ccccc}
\hline \multirow{2}{*}{ Stone } & \multicolumn{3}{c}{ Perdarahan (ml) } & \\
\cline { 2 - 4 } Burden & $<100$ & $100-200$ & $>200$ & p \\
& $\mathrm{n}(\%)$ & $\mathrm{n}(\%)$ & $\mathrm{n}(\%)$ & \\
\hline$<3 \mathrm{~cm}$ & $0(0)$ & $0(0)$ & $0(0)$ & \\
$3-5 \mathrm{~cm}$ & $2(40)$ & $2(40)$ & $1(20.0)$ & $0,866^{*}$ \\
$>5 \mathrm{~cm}$ & $21(50)$ & $10(23,8)$ & $11(26.2)$ & \\
\hline Total & $\mathbf{2 3 ( 4 8 , 9 )} \mathbf{1 2 ( 2 5 , 5 )} \mathbf{1 2 ( 2 5 . 5 )}$ & \\
\hline
\end{tabular}

*Uji Kruskal-Wallis

Tabel 4. Analisis hubungan antara Stone Burden terhadap Batu Sisa pada PCNL

\begin{tabular}{cccr}
\hline Stone & \multicolumn{2}{c}{ Batu Sisa } & \multirow{2}{*}{ p } \\
\cline { 2 - 3 } Burden & Ya & Tidak & \\
\hline$<3 \mathrm{~cm}$ & $0(0)$ & $3(100)$ & \\
$3-5 \mathrm{~cm}$ & $4(21,1)$ & $15(78,9)$ & \multirow{2}{*}{$0,445^{*}$} \\
$>5 \mathrm{~cm}$ & $14(29,8)$ & $33(70,2)$ & \\
\hline Total & $\mathbf{1 8 ( 2 6 , 1 )}$ & $\mathbf{5 1 ( 7 3 , 9 )}$ & \\
\hline
\end{tabular}

*Uji Kruskal-Wallis

Tabel 5. Analisis hubungan antara Stone Burden terhadap Batu Sisa pada Operasi Terbuka

\begin{tabular}{cccc}
\hline Stone & \multicolumn{2}{c}{ Batu Sisa } & \multirow{2}{*}{ p } \\
\cline { 2 - 3 } Burden & Ya & Tidak & \\
\hline$<3 \mathrm{~cm}$ & $0(0)$ & $0(0)$ & \\
$3-5 \mathrm{~cm}$ & $2(40)$ & $3(60)$ & \\
$>5 \mathrm{~cm}$ & $15(35,7)$ & $27(64,3)$ & $0,852^{*}$ \\
\hline Total & $\mathbf{1 7 ( 3 6 , 2 )}$ & $\mathbf{3 0}(\mathbf{6 3 , 8})$ & \\
\hline
\end{tabular}

*Uji Kruskal-Wallis 
Tabel 6. Analisis hubungan antara Stone Burden terhadap Lama Operasi pada PCNL

\begin{tabular}{cccc}
\hline $\begin{array}{c}\text { Stone } \\
\text { Burden }\end{array}$ & n & $\begin{array}{c}\text { Durasi Operasi } \\
\text { (median) menit }\end{array}$ & p \\
\hline$<3 \mathrm{~cm}$ & 3 & $150(120-150)$ & \\
$3-5 \mathrm{~cm}$ & 19 & $140(100-210)$ & $0,004^{*}$ \\
$>5 \mathrm{~cm}$ & 47 & $150(110-210)$ & \\
\hline
\end{tabular}

*Uji Kruskal-Wallis. Uji post hoc MannWhitney U: $3-5 \mathrm{~cm}$ vs $>5 \mathrm{~cm}(\mathrm{p}=0,002) ;<3 \mathrm{~cm}$ vs $3-5 \mathrm{~cm}$; $<3 \mathrm{~cm}$ vs $>5 \mathrm{~cm} \quad(\mathrm{p}>0,05)$. Data disajikan dalam Median (Min-Max)

Tabel 7. Analisis hubungan antara Stone Burden terhadap Lama Operasi pada Operasi Terbuka

\begin{tabular}{cccc}
\hline $\begin{array}{c}\text { Stone } \\
\text { Burden }\end{array}$ & n & $\begin{array}{c}\text { Durasi Operasi } \\
(\text { median) menit }\end{array}$ & $\mathbf{p}$ \\
\hline $3-5 \mathrm{~cm}$ & 5 & $170(120-190)$ & $0,02 *$ \\
$>5 \mathrm{~cm}$ & 42 & $200(150-300)$ & \\
\hline
\end{tabular}

*Uji Kruskal-Wallis. Uji post hoc MannWhitney U: $3-5 \mathrm{~cm}$ vs $>5 \mathrm{~cm}(\mathrm{p}=0,02)$. Data disajikan dalam Median (Min-Max)

Tabel 8. Analisis hubungan antara Letak Batu terhadap Jumlah Perdarahan pada PCNL

\begin{tabular}{ccccc}
\hline \multirow{2}{*}{$\begin{array}{c}\text { Letak } \\
\text { Batu }\end{array}$} & \multicolumn{3}{c}{ Perdarahan (ml) } & \\
\cline { 2 - 4 } & $\mathrm{n}(\%)$ & $\mathrm{n}(\%)$ & $\mathrm{n}(\%)$ & \\
\hline Staghorn & $12(35,3)$ & $19(55,9)$ & $3(8,8)$ & \\
Multipel & $6(40)$ & $5(33,3)$ & $4(26,7)$ & $0,648^{*}$ \\
Pielum & $11(55)$ & $5(25)$ & $4(20)$ & \\
\hline Total & $\mathbf{2 9 ( 4 2 )}$ & $\mathbf{2 9 ( 4 2 )}$ & $\mathbf{1 1}(\mathbf{1 6})$ & \\
\hline
\end{tabular}

*Uji Kruskal-Wallis

Tabel 9. Analisis hubungan antara Letak Batu terhadap Jumlah Perdarahan pada Operasi Terbuka

\begin{tabular}{ccccc}
\hline \multirow{2}{*}{$\begin{array}{c}\text { Letak } \\
\text { Batu }\end{array}$} & \multicolumn{3}{c}{ Perdarahan (ml) } & \\
\cline { 2 - 4 } & $\mathrm{n}(\%)$ & $\mathrm{n}(\%)$ & $\mathrm{n}(\%)$ & \\
\hline Staghorn & $16(51,6)$ & $8(25,8)$ & $7(22,6)$ & \\
Multipel & $1(14,3)$ & $2(28,6)$ & $4(57,1)$ & $0,058^{*}$ \\
Pielum & $6(66,7)$ & $2(22,2)$ & $1(11,1)$ & \\
\hline Total & $\mathbf{2 3}(\mathbf{4 9})$ & $\mathbf{1 2}(\mathbf{2 5 , 5})$ & $\mathbf{1 2}(\mathbf{2 5 , 5})$ & \\
\hline
\end{tabular}

*Uji Kruskal-Wallis
Tabel 10. Analisis hubungan antara Letak Batu terhadap Batu Sisa pada PCNL

\begin{tabular}{cccc}
\hline Letak & \multicolumn{2}{c}{ Batu Sisa } & \multirow{2}{*}{ p } \\
\cline { 2 - 3 } Batu & Ya & Tidak & \\
\hline Staghorn & $9(26,5)$ & $25(73,5)$ & \\
Multipel & $5(33,3)$ & $10(66,7)$ & 0 \\
Pielum & $4(20)$ & $16(80)$ & \\
\hline Total & $\mathbf{1 8 ( 2 6 , 1 )}$ & $\mathbf{5 1 ( 7 3 , 9 )}$ & \\
\hline *Uji Chi-Square & &
\end{tabular}

Tabel 11. Analisis hubungan antara Letak Batu terhadap Batu Sisa pada Operasi Terbuka

\begin{tabular}{cccc}
\hline Letak & \multicolumn{2}{c}{ Batu Sisa } & \multirow{2}{*}{ p } \\
\cline { 2 - 3 } Batu & Ya & Tidak & \\
\hline Staghorn & $15(48,4)$ & $16(51,6)$ & \\
Multipel & $1(14,3)$ & $6(85,7)$ & \multirow{2}{*}{$0,056^{*}$} \\
Pielum & $1(11,1)$ & $8(88,9)$ & \\
\hline Total & $\mathbf{1 7 ( 3 6 , 2 )}$ & $\mathbf{3 0}(\mathbf{6 3 , 8})$ & \\
\hline
\end{tabular}

*Uji Kruskal-Wallis

Pada tabel 8, 9, 10, dan 11 ditampilkan pengkajian hubungan antara letak batu dengan perdarahan dan batu sisa. Dari hasil di atas diperoleh bahwa tidak terdapat hubungan bermakna antara parameterparameter tersebut baik pada kelompok PCNL maupun pada kelompok operasi terbuka $(p>0,05)$.

Tabel 12. Analisis hubungan antara Letak Batu terhadap Lama Operasi pada PCNL

\begin{tabular}{cccc}
\hline $\begin{array}{c}\text { Letak } \\
\text { Batu }\end{array}$ & n & $\begin{array}{c}\text { Durasi Operasi } \\
\text { (median) menit }\end{array}$ & p \\
\hline Staghorn & 34 & $160(100-210)$ & \\
Multipel & 15 & $150(100-200)$ & $0,001^{*}$ \\
Pielum & 20 & $130(100-190)$ & \\
*Uji Kruskal-Wallis. Uji post hoc & Mann
\end{tabular}
Whitney U: staghorn vs pielum $(\mathrm{p}<0,001)$; staghorn vs multipel; pielum vs mutipel. Data disajikan dalam Median (min-max) 
Tabel 13. Analisis hubungan antara Letak Batu terhadap Lama Operasi pada Operasi Terbuka

\begin{tabular}{cccc}
\hline $\begin{array}{c}\text { Letak } \\
\text { Batu }\end{array}$ & n & $\begin{array}{c}\text { Durasi Operasi } \\
\text { (median) menit }\end{array}$ & p \\
\hline Staghorn & 31 & $200(120-300)$ & \\
Multipel & 7 & $200(150-280)$ & $0,038^{*}$ \\
Pielum & 9 & $180(150-210)$ & \\
\hline
\end{tabular}

*Uji Kruskal-Wallis. Uji post hoc Mann Whitney U: staghorn vs pielum $(\mathrm{p}<0,011)$; staghorn vs multipel; pielum vs mutipel. Data disajikan dalam Median (min-max)

Pada tabel 12 dan 13 ditampilkan pengkajian hubungan antara letak batu dengan lama operasi. Dari hasil diatas diperoleh hubungan bermakna antara letak batu dengan lama operasi pada kelompok PCNL dan kelompok operasi terbuka $(\mathrm{p}<0,05)$ terutama pada batu staghorn dan batu pielum.

\section{DISKUSI}

Pada penelitian ini, data diambil dari prosedur PCNL dan operasi terbuka pada batu dengan stone burden lebih dari $2 \mathrm{~cm}$. Hal ini sesuai dengan EAU (European Association of Urology) guideline 2014. Berdasarkan EAU guideline 2014, PCNL merupakan lini pertama tindakan pada batu ginjal berukuran lebih dari $20 \mathrm{~mm}$. Pada batu berukuran 10-20 mm di kaliks inferior, PCNL merupakan pilihan apabila tidak memenuhi persyaratan untuk dilakukan ESWL, yakni sudut infundibulopelvis yang tajam, tinggi kaliks lebih dari $10 \mathrm{~mm}$, dan lebar infundibulum kurang dari $5 \mathrm{~mm}$. Sedangkan indikasi operasi terbuka pada batu ginjal antara lain stone burden yang kompleks, gagal ESWL, PCNL, atau RIRS (retrograde intrarenal surgery), adanya abnormalitas anatomi, obesitas, deformitas skeletal, komorbiditas, bersamaan dengan operasi terbuka lainnya, gagal ginjal, pilihan pasien, dan batu pada ginjal ektopik, yang mana ESWL dan akses perkutan sulit dilakukan. ${ }^{11-13}$

Berdasarkan hasil studi Al-Kohlany et $a l$, PCNL dan operasi terbuka memiliki angka bebas batu yang sedikit berbeda yakni $49 \%$ dan $66 \%$ secara berurutan terhadap batu cetak ginjal. ${ }^{14}$ Siavash Falahatkar pada tahun 2009 pada penilitiannya menyatakan angka bebas batu pada PCNL dan operasi terbuka sebanyak $81,9 \%$ dan $91,6 \%$ secara berurutan. ${ }^{15}$ Namun pada penelitian ini ditemukan hasil yang tidak berbeda bermakna terhadap angka bebas batu pada kedua kelompok tersebut, yakni PCNL 73,9\% dan operasi terbuka 63,8\% (p>0,05). Dengan kata lain, PCNL dapat menyaingi efektivitas operasi terbuka dalam bersihan batu. Hal ini dapat dipengaruhi beberapa faktor, meliputi stone burden, letak maupun kompleksitas batu pada pasien yang menjalani operasi terbuka lebih kompleks daripada pasien PCNL.

Dalam hal komplikasi intraoperatif, angka kejadian perdarahan tidak berbeda bermakna antara kedua kelompok secara keseluruhan, walaupun pada kelompok operasi terbuka memiliki jumlah persentase perdarahan lebih dari $200 \mathrm{~mL}$ yang lebih besar daripada kelompok PCNL. Demikian juga halnya dengan transfusi yang tidak berbeda bermakna antara kedua kelompok. Padahal, pada studi sebelumnya diperoleh data bahwa insidensi komplikasi pada PCNL lebih kecil daripada operasi terbuka $(\mathrm{p}<0,05) \cdot{ }^{14,15}$ Komplikasi yang dimaksud antara lain perdarahan, termasuk yang membutuhkan transfusi darah, cedera pleura, cedera ureter, cedera kolon, demam paska operasi, dan sepsis paska operasi. ${ }^{14,15,17,18}$ Pada tindakan PCNL maupun operasi terbuka di RSPAD Gatot Soebroto tidak ditemukan adanya cedera pleura, cedera ureter, maupun cedera kolon. 
Komplikasi yang terjadi pada penelitian kami berupa demam paska operasi yang memiliki perbedaan bermakna antara PCNL dan operasi terbuka.

Pada penelitian ini PCNL memiliki waktu operasi yang lebih singkat secara bermakna daripada operasi terbuka. Hal ini didukung oleh hasil studi yang menunjukkan perbedaan serupa pada PCNL dan operasi terbuka $(127 \pm 30$ dan 204 \pm 31 menit; $p<0,05) .{ }^{14}$

Pada penelitian ini terbukti bahwa lama rawat paska operasi PCNL lebih pendek daripada operasi terbuka. Hasil yang diperoleh secara bermakna ini didukung oleh studi sebelumnya dengan lama rawat PCNL lebih pendek daripada operasi terbuka $(6,4 \pm 4,2$ dan $10 \pm 4,2$ hari; $\mathrm{p}<0,001) .{ }^{14}$

Baik kelompok PCNL maupun kelompok operasi terbuka menunjukkan tidak terdapat hubungan antara stone burden dan letak batu terhadap perdarahan maupun batu sisa. Terdapat hubungan yang bermakna pada stone burden dan letak batu terhadap lama operasi pada kedua kelompok tersebut $(\mathrm{p}<0,05)$. Padahal menurut literatur, stone burden dan kompleksitas maupun letak batu merupakan salah satu faktor utama penentu komplikasi dan efektifitas tindakan operasi batu ginjal. ${ }^{10,11,15-17}$

Secara keseluruhan, PCNL memiliki kesamaan dengan operasi terbuka dalam hal stone free rate dan risiko perdarahan. Sedangkan dalam parameter lama rawat paska operasi dan waktu operasi, PCNL memiliki keunggulan daripada operasi terbuka karena dengan waktu yang lebih singkat, kemungkinan adanya infeksi dan risiko komplikasi paska operasi lainnya dapat lebih minimal. ${ }^{14-19}$

\section{SIMPULAN}

PCNL memerlukan lama operasi dan lama rawat paska operasi yang lebih singkat, serta komplikasi demam paska operasi yang lebih sedikit, dibandingkan operasi terbuka. Namun demikian, untuk angka bebas batu dan jumlah perdarahan, tidak berbeda bermakna pada kedua kelompok. Terdapat hubungan yang bermakna secara statistik pada lama operasi dengan stone burden dan letak batu pada kedua kelompok.

Sehingga dapat dikatakan bahwa PCNL merupakan prosedur minimal invasif yang efektif dan aman dalam tatalaksana batu ginjal lebih besar dari $2 \mathrm{~cm}$ atau pada kasus batu ginjal kompleks.

\section{DAFTAR PUSTAKA}

1. Romero V, Akpinar H, Assimos DG. Kidney Stones: A Global Picture of Prevalence, Incidence, and Associated Risk Factors. Rev Urol. 2010;12:e8696.

2. Curhan GC, Rimm EB, Willett WC, et al. Regional Variation in Nephrolithiasis Incidence and Prevalence Among United States Men. J Urol. 1994;151:838-41.

3. Stamatelou KK, Francis ME, Jones CA, et al. Time Trends in Reported Prevalence of Kidney Stones in the United States: 1976-1994. Kidney Int. 2003;63:1817-23.

4. Soucie JM, Thun MJ, Coates RJ, et al. Demographic and Geographic Variability of Kidney Stones in the United States. Kidney Int. 1994;46:8939.

5. Hiatt RA, Dales LG, Friedman GD, et al. Frequency of Urolithiasis in a Prepaid Medical Care Program. Am J Epidemiol. 1982;115:255-65. 
6. Rahardjo D, Hamid R. Perkembangan Penatalaksanaan Batu Ginjal di RSCM tahun 1997-2002. J I Bedah Indones. 2004;32:58-63.

7. Ogg CS, Saxton HM, Cameron JS. Percutaneous Needle Nephrostomy. Br Med J 1969;4:657-60.

8. Fernström I, Johansson B. Percutaneous Pyelolithotomy. A New Extraction Technique. Scand J Urol Nephrol. 1976;10:257-9.

9. Badlani G, Eshghi M, Smith AD. Percutaneous Surgery for Ureteropelvic Junction Obstruction (endopyelotomy): Technique and Early Results. J Urol. 1986;135:26-8.

10. Wolf JS. Percutaneous Approach to the Upper Collecting System. Campbell Walsh Urology $10^{\text {th }}$ ed. Philadelphia: WB Saunders Co; 2012.p.1324-56.

11. Matlaga BR, Lingeman JE. Surgical Management of Upper Urinary Tract Calculi. Campbell Walsh Urology $10^{\text {th }}$ ed. Philadelphia: WB Saunders Co; 2012.p.1357-410.

12. Turk C, Knoll T, Petrik A, et al. Guidelines on Urolithiasis. European Association of Urology Guidelines. 2014.

13. Preminger GM, Assimos DG, Lingeman JE, et al. Chapter 1: AUA Guideline on Management of Staghorn Calculi: Diagnosis and Treatment Recommendations. J Urol. 2005;173:1991-2000.

14. Al-Kohlany KM, Shokeir AA, Mosbah A, et al. Treatment of Complete Staghorn Stones: A Prospective Randomized Comparison of Open Surgery versus Percutaneous Nephrolithotomy. $J \quad$ Urol. 2005;173:469-73.

15. Falahatkar S. Percutaneous Nephrolithotomy Versus Open Surgery for Patients with Renal Staghorn Stones. Uro Today Int J. 2009;2.

16. Khalaf I, Salih E, El-Mallah E, et al. The Outcome of Open Renal Stone Surgery Calls for Limitation of its use: A single Institution experience. African J Urol. 2013;19:58-65.

17. Aghamir SM, Mojtahedzadeh M, Meysamie A, et al. Comparison of Stress Responses Between PCNL and Open Nephrolithotomy. J Endourol. 2008;22:2495-500.

18. Taylor E, Miller J, Chi $\mathrm{T}$, et al. Complication associated with percutaneous nephrolithotomy. Transl Androl Urol. 2012;1:223-28.

19. Vicentini FC, Gomes CM, Danilovic A, et al. Percutaneous nephrolithotomy: current concepts. Indian $J$ Urol. 2009;25:4-10. 